\title{
A Study of the Metacognition Levels of Student Teachers On The Basis Of Their Learning Styles
}

\author{
Dr. Geeta Shetty \\ Department of Education, St. Xavier's Institute of Education, India
}

\begin{abstract}
Metacognition and Learning styles are significant factors that influence learning. Metacognition is the awareness of one's own patterns of thinking. Metacognitive awareness helps a learner to be self directed and self regulated. Learners exhibit different learning styles that influence the way they make sense of the learning experiences. The study aimed at finding out the learning styles that showed higher levels of Metacognition. The Descriptive Survey Method was adopted for the study. A sample of 172 student teachers were administered the Metacognitive Awareness Inventory (Schraw and Dennison-1994) and The Myers-Briggs Type Indicator (MBTI -1977). The data collected was analyzed using the ' $t$-test' to compare the Mean scores on Metacognition of student teachers having different learning styles. The results showed that the combination that emerged the highest among student teachers was ESFJ (Extraversion, Sensing, Feeling and Judging). However student teachers with the learning styles Introversion and Thinking were found to be significantly higher in Metacognition as compared to student teachers with the learning styles Extraversion and Feeling.
\end{abstract}

Key words: Metacognition, Learning styles, student teachers

\section{Introduction}

Learning is not the passive acceptance of knowledge that exists out there, but it is a process that involves an active engagement of the learner with the world. The mind interprets the experiences provided by the environment. The mind and its thought process together aid in the construction of meaning. The construction of meaning depends upon the pattern in which the mind functions also called the learning styles. Learning involves not just cognitive processes but also strategies that regulate and monitor these processes. Learning involves information processing that in turn requires cognition as well as metacognition. The stages of the information processing cycle essentially relate to input, cognition and output and the importance of learning styles as a crucial factor in all these stages cannot be disputed.

\subsection{Aim of the Study}

The broad aim of the study was to study the learning styles of student teachers on the basis of their levels of metacognition.

\subsection{Review of Related Literature \\ 1.2.1 Studies on Metacognition}

Howard, et al. (2001a, 2001b) [1] found that metacognitive self-regulatory skills were so important for individual students that even classroom-level variables such as the type of instruction received did little to take away from this effect. And that knowledge of cognition, objectivity, and problem representation predicted successful problem solving and that high level of metacognitive self-regulation compensated for low overall abilities. In a study on 'Self-Regulation in Academic Writing tasks' conducted by Hammann L. (2005) [2] it was found that both knowledge and regulation of cognition were positively related to writing enjoyment, and knowledge of cognition was negatively related to beliefs of ability as a fixed entity. Rezvan S., Ahmadi S. and Abedi M. (2006) [3] suggested that metacognitive training had increased the academic achievement average as well as the happiness scores average of the experimental group. Stewart P.W., Cooper. S.S., and Moulding L.R. (2007) [4] found that the experienced teachers had significantly higher scores than pre-service teachers in Metacognitive Knowledge, Metacognitive Regulation and total MAI scores.

Coutinho, S. (2008) [5] revealed that students with effective metacognitive strategies have strong belief in their capabilities to successfully perform a task. Shetty G. (2008) [6] conducted a study titled, "A Study of the Effectiveness of Problem Based Learning in Developing Metacognitive Skills in Student Teachers". The findings reveal that PBL is effective in developing Metacognitive skills in general and more specifically in the Procedural Knowledge aspect of Knowledge of Cognition and the Planning and Information Management aspects of Regulation of Cognition. The Experimental group has also scored significantly higher than the Control group in the Regulation of Cognition aspect of Metacognitive Awareness. The Experimental group has also scored significantly higher than the Control group in their Achievement test. This shows that even as PBL develops skills, it does not compromise on the acquisition of content related knowledge. 
Topcu, A., and Ubuz B. (2008) [7] studied 'The Effects of Metacognitive Knowledge on the Pre-service Teachers' Participation in the Asynchronous Online Forum' in which it was found that metacognitive knowledge increases the learners' ability to be independent learners, which is an indispensable characteristic of the distant learner. Kapadia, R. (2009) [8] studied metacognition of secondary school students in relation to learning environment and teacher competencies. Results showed that female students possessed higher metacognition than male students, both for total metacognition as well as component wise metacognition scores. A direct and substantial correlation was obtained between metacognition and learning environment as well as between metacogntion and teacher competencies across genders and all school types. Task orientation component of learning environment and technical competency component of teacher competency were found to be significant predictors of most of the components of metacognition.

1.2.2 Studies on Learning Styles

Clump, M. (2003) [9] conducted a study titled 'Do psychology and biology majors differ in their study processes and learning styles?' The study suggested that psychology majors use more Deep Approach techniques while studying than their cohort group of biology majors. There was no significant differences between upper and lower level students in learning styles. Wilson J., Lawson K., Novak S., Shah S., Salzman R. (2006) [10] studied Pharmacy Students' Learning Styles Before and After a Problem-based Learning Experience. Results showed that while PBL appears to be a teaching style that is conducive to the learning preferences of this cohort of pharmacy students, significant changes in learning styles were noted after completing the PBL experience. These changes may reflect difficulties that occurred in adapting from a didactic teaching style to PBL, and specifically, difficulties in adjusting to participating in a group learning experience. Liu Y. (2007) [11] conducted a study titled 'A Comparative Study of Learning Styles between Online and Traditional Students'. Specifically, at the end of the course, online students seemed to have a higher preference for peer interaction, competition, interaction with the instructor, details of the course materials, independence, authority, reading, direct experiences, and clear goal setting than their counterparts in the Face to Face section. Akkoyunlu, B., \& Soylu, M. Y. (2008) [12] found that students' views on blended learning process ,such as ease of use of the web environment, evaluation, face to face environment etc., differ according to their learning styles. Shannon S. (2008) [13] did a study on 'Using Metacognitive Strategies and Learning Styles to Create Self-Directed Learners' Throughout the study, the researcher found that no matter the learning style a student might prefer, all of the students, whether consciously or unconsciously, were continuously evaluating their performance and their progress. Teaching students Metacognitive strategies is a valuable skill that helps students become more self-directed learners.

The following observations were made after the Review of Related Literature;

- Metacognition improves performance and perception of learning.

- Metacognitive skills can be developed.

- Different individuals have different levels of Metacognitive awareness.

- Individuals differing in learning styles perceive their learning environment differently.

- Individuals with different Learning styles adopt different Metacognitive strategies.

\subsection{Need for the Study}

The aim of education wide over focuses on enhancing student's cognitive skills. There has been a surge for understanding ways to improve student's cognitive abilities therefore. In other words, cognitive skills focus on improving students thinking abilities. In the past few years however, educational psychologists have shifted gears one step ahead towards helping students not only think but also regulate their thinking. The importance of developing student's metacognition has been coming to the fore. Research reviews highlight that like any other psychological concept; metacognition of a student could have a bearing on various other cognitive abilities. It is therefore necessary to identify the relationship that may exist between student's metacognition and their learning styles. The research review also indicates that not many studies have been conducted to study how learning styles influence the levels of metacognition among student teachers. This was important since the focus of developing desired metacognitive skills requires a direction.

\subsection{Conceptual Framework \\ 1.4.1 Metacognition}

Metacognition refers to the cognitive control and monitoring of first-order cognitive processes. "Meta" means "beyond" and "cognition" means, "to know." Metacognition means to go beyond just knowing to understanding how you know what you know.

Flavell (1979) [14] defines metacognition as, "knowledge and cognition about cognitive phenomena". Metacognition is a dialogue between the learner and his/her thought processes that results in monitoring and regulation of learning. It is thus an ability to plan strategies for producing what information is needed, to be 
conscious of one's own steps and strategies during the act of problem solving and to reflect on and evaluate the productivity of one's own thinking

According to Flavell (1993) [15], metacognition is composed of both metacognitive knowledge and metacognitive regulation.

Metacognitive Knowledge: Metacognitive knowledge refers to acquired knowledge about cognitive processes, knowledge that can be used to control cognitive processes. Flavell further divides metacognitive knowledge into three categories: knowledge of person variables, task variables and strategy variables.

Knowledge of person variables refers to general knowledge about how human beings learn and process information, as well as individual knowledge of one's own learning processes.

Knowledge of task variables include knowledge about the nature of the task as well as the type of processing demands that it will place upon the individual.

Knowledge about strategy variables include knowledge about both cognitive and metacognitive strategies, as well as conditional knowledge about when and where it is appropriate to use such strategies.

Metacognitive Regulation: Metacognitive experiences involve the use of metacognitive strategies or metacognitive regulation (Brown, 2002) [16]. Metacognitive strategies are sequential processes that one uses to control cognitive activities, and to ensure that a cognitive goal has been met. These processes help to regulate and oversee learning, and consist of planning and monitoring cognitive activities, as well as checking the outcomes of those activities.

\section{Metacognition can be understood as;}

\section{A) Awareness Of The Self}

- An awareness of one's own thought processes in a particular learning situation. It is being able to recognize it and also describe it. The learner is able to realize the pattern of thinking that takes place in his/her mind in a learning situation.

An awareness of the content of one's thoughts in the learning situation. In particular it is the ability in an individual to identify how much he/she already knows about the task, and how much he/she would be needed to know for the task.

- An awareness in an individual of his/her innate capacity to process information and also be able to describe that capacity.

An awareness of one's own feelings about the learning situation. This also is not just to recognize the feelings but also be able to verbalize them.

B) Management Of The Self

An ability to take charge of one's own thought processes and monitor them with respect to the learning task.

C) Manscious effort to unde

- An ability to set short term and long term goals for the task.

- An ability to identify and apply strategies for regulation of learning based on an analysis of the self.

- An ability to adapt or modify learning strategies as required for the task.

Metacognition involves a process of systematic inquiry done by an individual at every phase of the learning task as illustrated in Table 1 given below;

\section{TABLE 1}

Metacognitive inquiry at every stage of a task as part of the Metacognitive process

\begin{tabular}{|c|c|c|}
\hline Before the task & During the task & After the task \\
\hline $\begin{array}{l}\text { Have I done this task before? } \\
\text { What do I know about the } \\
\text { task? } \\
\text { How do I tackle it? } \\
\text { How much knowledge do I } \\
\text { have to tackle the task? } \\
\text { How much time would I need } \\
\text { to complete the task? } \\
\text { How do I feel about this task? }\end{array}$ & $\begin{array}{l}>\quad \text { What do I have to do to accomplish } \\
\text { this task? } \\
\text { How should I tackle it? Should I } \\
\text { tackle it the same way as before? } \\
>\quad \text { Am I on the right track? } \\
\text { Do I need to think of alternative } \\
\text { strategies? } \\
\text { Are the resources selected by me } \\
\text { relevant and sufficient to tackle the } \\
\text { task? } \\
>\quad \text { Have I allotted the right amount of } \\
\text { time for the task? } \\
>\quad \text { Have I analyzed the task properly? } \\
>\quad \text { How do I feel while performing the } \\
\text { task? }\end{array}$ & $\begin{array}{l}\text { What did I learn? } \\
>\quad \text { What did I find easy? } \\
>\quad \text { What was difficult? } \\
>\quad \text { Why did I find it easy or difficult? } \\
\text { effective? } \\
\text { Would the task have been better if I } \\
\text { had adopted some other strategies? } \\
>\quad \text { What are the mistakes I made? } \\
>\quad \text { What were some of the good } \\
\text { decisions I had taken during the } \\
\text { task? } \\
\text { Did I manage my time effectively? } \\
\text { How do I feel about the entire } \\
\text { process? }\end{array}$ \\
\hline
\end{tabular}




\subsubsection{Why Metacognition?}

Metacognitive ability is important because it produces the powerful knowledge that enables students to control their learning by demonstrating a conscious application of cognitive strategies.

- Metacognition for conscious engagement: Very often students become passive recipients of information leading to less engagement and involvement in the learning process. The Metacognitive process helps students dwell on and analyze the learning task. This makes the students mindful learners. Mindfulness can be thought of as creating an optimally receptive state for new learning and experience, increasing the likelihood that appropriate metacognitive skills will be selected and employed. (Garland, 2007 [17]; Thomas, 2006) [18]. Mindfulness practice requires the activation of metacognitive knowledge, monitoring, and control (Wells, 2005) [19].

- Metacognition for Reflective education: One of the roles of education is to develop reflective practitioners. Metacognition involves deep reflection on the cognitive processes and then regulation of those processes to maximize learning. Metacognitive skills help learners to reflect on the task at hand and also "in action" and "on action". It also helps learners to reflect on their own reflections, thus leading to learning that is self directed, goal oriented and self evaluated.

- Metacognition for greater experiential learning: Experiential learning is a process that takes place when the learner gains insights from direct experiences encountered by him/her. To gain these insights the learner has to be conscious of the learning experiences at hand and the strategies that would help in the learning process. Therefore greater the Metacognitive awareness greater would be the benefits obtained by the learners from the experiential process.

- Metacognition for enhanced thinking: Besides helping in reflective thinking, Metacognition also enhances analytical and critical thinking thus enabling the learners to gain an appropriate perspective of the learning task at hand.

- Metacognition for deep learning: Metacognition does away with surface learning and helps learners go through various loops of learning thereby leading to deeper understanding. The learners are able to know and thereby tap the relevant resources for gaining deep learning.

- Metacognition for greater accountability: Students used to metacognitive thinking, assume greater responsibility for their own learning. They are aware of their own strategies and are open to modifications in their thought processes if the situation demands. Training in Metacognitive skills would help students plan their tasks and activities more effectively.

- Metacognition for lifelong learning: Most students drop out or do not take up further studies, as they lack the skills that are required to be self directed learners. A practice of Metacognitive skills would help in lifelong learning as they get accustomed to goal setting and strategizing their learning.

Self-awareness promotes self-regulation. Self regulation is the ability of the learner to control interest, attitude and effort towards a task or a goal. Metacognitive knowledge and metacognitive regulation ensures selfawareness and the use of self-regulatory learning strategies in order to acquire better cognition.

\subsubsection{Learning Styles}

Where metacognition is "thinking about thinking", learning styles simply represents "thinking about learning". Educators have for many years, noticed that some students prefer certain methods of learning than others. Learning styles form a student's unique learning preference and help instructors in the planning of learning/teaching environment. Learning style can be defined as a preferred way of thinking and processing information and it is unique to the learner.

Myers and Briggs adapted Carl Jung's four dimensions of personality and evolved the Myers-Briggs Type Indicator (MBTI). The MBTI provides information about the ways learners prefer to perceive meaning, to express values and commitment and to interact with the world. In the simplified version, personality typing as defined by Myers and Briggs [20] assumes that much of our personality can be defined by dividing it into four independent preference areas or scales: energizing, attending, deciding, and living. Within each scale there is a preference for one of two opposites that define the scale. This makes for a total of 16 different combinations, each of which defines one particular and unique personality archetype.

Following are the preferences for each of the four scales:

1. Energizing - How a person is energized:

Extroversion (E) - Preference for drawing energy from the outside world of people, activities or things.

Introversion (I) - Preference for drawing energy from one's internal world of ideas, emotions, or impressions.

2. Attending - What a person pays attention to:

Sensing (S) - Preference for using the senses to notice what is real. 
Intuition (N) - Preference for using the imagination to envision what is possible - to look beyond the five senses. Jung calls this "unconscious perceiving".

3. Deciding - How a person decides:

Thinking (T) - Preference for organizing and structuring information to decide in a logical, objective way.

Feeling (F) - Preference for organizing and structuring information to decide in a personal, valueoriented way.

4. Living - Life style a person prefers:

Judgment (J) - Preference for living a planned and organized life.

Perception (P) - Preference for living a spontaneous and flexible life.

The Learning Styles of individuals are known from the combination of the four preferences. In all sixteen combinations have been identified.

What the Combinations mean? Myers and Briggs [21]

ISTJ- Serious, quiet, earn success by concentration and thoroughness. Practical, orderly, matter-of-fact, logical, realistic, dependable. See to it that everything is well organized. Take responsibility. Make up their minds as to what should be accomplished and work toward is steadily, regardless of protests or distractions

ISFJ- Quiet friendly, responsible, and conscientious. Work devotedly to meet their obligations. Lend stability to any project or group. Thorough, painstaking, accurate. Their interests are usually not technical. Can be patient with necessary details. Loyal, considerate, perceptive, concerned with how other people feel.

INFJ- Succeed by perseverance, originality, and desire to do whatever is needed or wanted. Put their best efforts into their work. Quietly forceful, conscientious, concerned for others. Respected for their firm principles. Likely to be honored and followed for their clear convictions as to how best to serve the common good.

INTJ- Usually have original minds and great drive for their own ideas and purposes. In fields that appeal to them, they have a fine power to organize a job and carry it out with or without help. Skeptical, critical, independent determined, sometimes stubborn. Must learn to yield less important points in order to win the most important

ISTP- Cool onlookers. Quiet, reserved, observing and analyzing life with detached curiosity and unexpected flashes of original humor. Usually interested in cause and effect-how and why mechanical things work, and in organizing facts use logical principles.

ISFP- Retiring, quiet, sensitive, kind, and modest about their abilities. Shun disagreements; do not force their opinions or values on others. Usually do not care to lead but are often loyal followers. Often relaxed about getting things done, because they enjoy the moment and do not want to spoil it by undue haste or exertion.

INFP- Full of enthusiasm and loyalties, but seldom talk of these until they know you well. Care about learning ideas, language, and independent projects of their own. Tend to undertake too much, then somehow get it done. Friendly, but often too absorbed in what they are doing to be sociable. Little concerned with possessions or physical surroundings.

INTP- Quiet and reserved. Especially enjoy theoretical or scientific pursuits. Like solving problems with logic and analysis. Usually interested mainly ideas, with little liking for parties or small talk. Tend to have sharply defined interests. Need careers where some strong interests can be used and useful.

ESTP- Good at on the spot problem solving. Do not worry-enjoy whatever comes along. Tend to like mechanical things and sports, with friends on the side. Adaptable, tolerant, generally conservative in values. Dislike long explanations. Are best with real things that can be worked, handled, taken apart, or put together.

ESFP- Outgoing, easygoing, accepting, enjoy everything and make things more fun for others by their enjoyment. Like sports and making things happen. Know what is going on and join in eagerly. Find remembering facts easier than mastering theories. Are best in situations that need sound common sense and practical ability with people as well as with things.

ENFP- Warmly enthusiastic, high spirited, ingenious, imaginative. Able to do almost anything that interests them. Quick with a solution for any difficulty and ready to help anyone with a problem. Often rely on their ability to improvise instead of preparing in advance. Can usually find compelling reasons for whatever they want.

ENTP- Quick, ingenious, good at many things. Stimulating company alert and outspoken. May argue for fun on either side of question. Resourceful in solving new and challenging problems but may neglect some routine assignments. Apt to turn to one new interest after another. Skillful in finding logical reasons for what they want. ESTJ Practical, realistic, matter of fact with a natural head for business and mechanics. Not interested in subjects they see no use for, but can apply themselves when necessary. Like to organize and run activities. May be good administrators, especially if they remember to consider others' feelings and points of view. 
ESFJ- Warm-hearted, talkative, popular, conscientious, born cooperators, active committee members. Need harmony and may be good at creating it. Always doing something nice for someone. Work best with encouragement and praise. Main interest is in things that directly and practically help people's lives

ENFJ- Responsive and responsible. Generally feel real concern for what others think or want, and try to handle things with due regard for the other person's feelings. Can present a proposal or lead a group discussion with ease and tact. Sociable, popular, sympathetic. Responsive to praise and criticism.

ENTJ- Hearty, frank, decisive leaders in activities. Usually good in anything that requires reasoning and intelligent talk, such as public speaking. Are usually well informed and enjoy adding to their fun of knowledge. May sometimes appear more positive and confident than their experience in the area warrants.

1.5 Significance of the Study

Educationists are constantly on the lookout for new and better ways of helping the learners to learn. Classroom interactions would not be only to impart information, but to develop in the learners the skills to regulate and monitor their learning patterns. One can change and become a better learner, if one wants to.

The study will contribute towards:

- Designing learning experiences to suit the learning styles of students.

- Developing metacognitive strategies that would be suitable for the different learning styles.

- Provide guidance to parents and guardians to enhance the metacognitive abilities of their wards on the basis of their learning styles.

The ultimate goal of understanding learning and learning styles is to create congruence between instruction or design and information processing, matching the respective styles of each. The study would help the researchers develop teaching strategies that would support the desired learning style for students to enhance their metacognition. The results of the study would help curriculum developers suggest modifications. It would further pave way for more research in the field.

\section{Objectives of the Study}

The following objectives were framed for the study;

1. To analyze the level of metacognitive awareness of student teachers.

2. To analyze the learning styles of student teachers.

3. To identify the learning styles of student teachers at different levels of metacognition.

4. To compare the levels of metacognition of student teachers with different learning styles.

\section{Hypothesis of the Study}

The null hypothesis for the study was as follows;

1. There is no significant difference in the level of Metacognition of student teachers with the following learning styles;

- $\quad$ Extroverts vs. Introverts

- $\quad$ Sensate vs. Intuitive

- $\quad$ Thinkers vs. Feelers

- Judgers vs. Perceivers

\section{Method of Study}

The present study was Descriptive in nature as it intended to study the metacognitive abilities and learning styles as they existed at present among student teachers.

\section{Sample}

Available sampling technique was used to select the colleges of education. Sample of the study included 172 student teachers from two colleges of education in Greater Mumbai. These colleges were selected on the basis of availability. The colleges were English medium colleges.

\section{Tools Used}

The following tools were used for the present study:-

1. Tool measuring levels of Metacognition: Metacognitive Awareness Inventory (Schraw and Dennison-1994) [22]

This is a 52-item self-report instrument of adolescent and adult metacognitive awareness. The items are based on the Brown (1987) two-component model of metacognition, Knowledge of Cognition and Regulation of Cognition. Internal consistency coefficient (r) ranges from 0.90 to 0.95 with a test-retest reliability of about 0.85 . 
2. Tool measuring Learning Styles: The Myers-Briggs Type Indicator (MBTI) -1977 [23]

The MBTI identifies four individual preferences or strengths that persons use in gathering information and making decisions, namely Extraversion or Introversion, Sensing or Intuition, Thinking or Feeling and Judging or Perceiving. Using four of the eight factors, a person's learning style is derived from a possible combination of 16 types. The MBTI has a test-retest reliability of 0.87 .

\section{Data Analysis}

The data gathered was subjected to Descriptive and Inferential analysis.

\subsection{Descriptive Analysis}

\subsubsection{Percentage Analysis}

On the basis of the data obtained on the Metacognitive Awareness Inventory, three groups were identified, namely Low level of Metacognitive Awareness (200 - 350); Average level of Metacognitive Awareness (350 500); High level of Metacognitive Awareness (above 500). TABLES 1 and 2 show the percentage of the number of student teachers showing the different learning styles with reference to their level of Metacognitive Awareness.

TABLE 1

The Percentage of Student teachers with different levels of Metacognition showing the different Learning Styles.

\begin{tabular}{|c|c|c|c|c|c|c|c|c|}
\hline Learning Styles & $\mathbf{E}$ & I & $\mathbf{S}$ & $\mathbf{N}$ & $\mathbf{T}$ & $\mathbf{F}$ & $\mathbf{J}$ & $\mathbf{P}$ \\
\hline $\begin{array}{l}\text { Percentage of student teachers with low level of } \\
\text { Metacognition }(\mathrm{N}=26)\end{array}$ & 65 & 35 & 88 & 12 & 46 & 54 & 92 & 8 \\
\hline $\begin{array}{l}\text { Percentage of student teachers with average level of } \\
\text { Metacognitive Awareness }(\mathrm{N}=106)\end{array}$ & 62 & 38 & 87 & 13 & 48 & 52 & 89 & 11 \\
\hline $\begin{array}{l}\text { Percentage of student teachers with high level of } \\
\text { Metacognitive Awareness }(\mathrm{N}=40)\end{array}$ & 55 & 45 & 88 & 12 & 55 & 45 & 93 & 7 \\
\hline
\end{tabular}

TABLE 2

The Percentage of Total Sample ( $N=172)$ showing the different Learning Styles

\begin{tabular}{|l|l|l|l|l|l|l|l|l|}
\hline Learning Styles & E & I & S & N & T & F & J & P \\
\hline Percentage & 61.05 & 38.95 & 87.21 & 12.79 & 49.42 & 50.58 & 90.12 & 9.88 \\
\hline
\end{tabular}

Discussion: A large percentage of the total sample of student teachers shows the Extraversion, Sensate, Feeling and Judging (ESFJ) Learning Styles. This trend is seen even with respect to the student teachers with low and average levels of Metacognitive awareness.

\section{Interpretation:}

- Thus a large percentage of the sample is ESFJ i.e. they are warm-hearted, talkative, popular, conscientious, born cooperators, active committee members; Need harmony and may be good at creating it; always doing something nice for someone; Work best with encouragement and praise; Main interest is in things that directly and practically help people's lives.

\subsubsection{Measures of Central Tendency}

TABLE 3 shows the Mean and Standard Deviation of the Scores on Metacognitive Awareness of student teachers having different Learning Styles.

TABLE 3

Mean and Standard Deviation of the Scores on Metacognition of student teachers having different Learning Styles.

\begin{tabular}{|c|c|c|c|}
\hline Learning Styles & $\mathbf{N}$ & Mean & Std. Deviation \\
\hline Extravert & 105 & 388.50 & 92.39 \\
\hline Introvert & 67 & 415.19 & 66.99 \\
\hline Sensate & 150 & 398.59 & 85.44 \\
\hline N (Intuitive) & 22 & 396.45 & 79.70 \\
\hline Thinker & 85 & 438.87 & 56.59 \\
\hline Feeler & 87 & 392.63 & 91.59 \\
\hline Judger & 155 & 398.08 & 86.82 \\
\hline Perceiver & 17 & 402.06 & 61.62 \\
\hline
\end{tabular}




\section{Discussion:}

- The Mean score on Metacognition of student teachers who are Introverts is higher than that of the student teachers who are Extraverts.

- The Mean score on Metacognition of student teachers who are Sensate is higher than that of the student teachers who are Intuitive.

- The Mean score on Metacognition of student teachers who are Thinkers is higher than that of the student teachers who are Feelers.

- The Mean score on Metacognition of student teachers who are Perceivers is higher than that of the student teachers who are Judgers.

\subsection{Inferential Analysis}

\section{Testing of the Hypothesis 1}

Table 4 shows the relevant statistics for the Comparison of Means of the Scores on Metacognition of student teachers with different Learning styles.

TABLE 4

Comparison of the Mean scores on Metacognitive Awareness of student teachers with different Learning styles.

\begin{tabular}{|l|c|c|c|}
\hline \multicolumn{1}{|c|}{ Learning Styles } & Means & t-Value & Level of Significance (df= 170) \\
\hline Extrovert & 388.50 & 2.19 & Significant at 0.05 level \\
\hline Introvert & 415.19 & 0.12 & Not Significant \\
\hline Sensate & 398.59 & & Significant at 0.01 level \\
\cline { 1 - 2 } N (Intuitive) & 396.45 & 3.99 & Not Significant \\
\cline { 1 - 2 } Thinker & 438.87 & 0.24 & \\
\cline { 1 - 2 } Judger & 392.63 & & \\
\hline Perceiver & 398.08 & & \\
\hline
\end{tabular}

For $\mathrm{df}=170, \mathrm{t}$-value at the 0.05 level (Table D from Garret H.E.) is 1.97 and at the 0.01 level is 2.60 Findings

There is a significant difference in the Mean score on Metacognitive Awareness of student teachers who are Extroverts and that of student teachers who are Introverts. Hence the null hypothesis is rejected.

- There is no significant difference in the Mean score on Metacognitive Awareness of student teachers who are Sensate and that of student teachers who are Intuitive. Hence the null hypothesis is accepted.

- There is a significant difference in the Mean score on Metacognitive Awareness of student teachers who are Thinkers and that of student teachers who are Feelers. Hence the null hypothesis is rejected.

- There is no significant difference in the Mean score on Metacognitive Awareness of student teachers who are Judgers and that of student teachers who are Perceivers. Hence the null hypothesis is accepted.

\section{Interpretation:}

- The Introverts are significantly higher than the Extroverts in Metacognition

- The student teachers who are Sensate and Intuitive show no significant difference in Metacognition.

- The Thinkers are significantly higher than the Feelers in Metacognition.

- The student teachers who are Judgers and Perceivers show no significant difference in Metacognition.

\section{Conclusion}

The study of metacognition has provided educational psychologists with insight about the cognitive processes involved in learning and what differentiates successful students from their less successful peers. It also holds several implications for instructional interventions, such as teaching students how to be more aware of their learning processes and products as well as how to regulate those processes for more effective learning. The task of educators is to acknowledge, cultivate, exploit and enhance the metacognitive capabilities of all learners. Metacognition, or awareness of the process of learning, is a critical ingredient to successful learning.

It is found that a student teacher who is an Introvert and a Thinker scores in Metacognition over those with the other learning styles. The learners with other learning styles would probably benefit with reflective practices done on a regular basis. By giving more occasions for quiet introspections on thinking patterns and regular journaling could help in the development of Metacognitive Awareness. Questioning and focused inquiry on thought patterns of students would help them to think metacognitively. Providing students with meaningful 
activities and collaborative learning opportunities would make them more reflective individuals. The result of metacognition is the conscious regulation and rearrangement of how one thinks in the face of complex problems requiring novel solutions. The importance of 'quiet time' should be emphasized as it helps learners to introspect, reflect and reform themselves.

\section{References:}

[1] Howard, B. et al., The influence of metacognitive self-regulation and ability levels on problem solving. A paper presented at the annual meeting of the American Educational Research Association, Seattle, Washington (2001).

[2] Hammann L., Self-Regulation in Academic Writing tasks. Retrieved on 15/06/11 from http://www.isetl.org/ijtlhe/pdf/IJTLHE14.pdf (2005).

[3] Rezvan S., Ahmadi, A., Abedi, R. (2006). The effects of metacognitive training on the academic achievement and happiness of Esfahan University conditional students retrieved on 13/12/06, from, http://surveys.canterbury.ac.nz/herdsa03/pdfsnon/N1171.pdf

[4] Stewart, P.W., Cooper, S. \& Moulding, L., Metacognitive development in professional educators in The Researcher, 21 (1), (2007).

[5] Coutinho, S., Self-efficacy, metacognition, and performance retrieved on $2^{\text {nd }}$ July, 2010 from http://www.highbeam.com/doc/1G1178452273.html (2008).

[6] Shetty G., A Study of the Effectiveness of Problem Based Learning in Developing Metacognitive Skills in Student Teachers, SNDT University, Mumbai, India (2008).

[7] Topcu, A., and Ubuz B., The Effects of Metacognitive Knowledge on the Pre-service Teachers' Participation in the Asynchronous Online Forum. Retrieved on 15/06/06 from http://www.ifets.info/journals/11_3/1.pdf (2008).

[8] Kapadia, R., Metacognition of secondary school students in relation to learning environment and teacher competencies, University of Mumbai, Mumbai, India (2009).

[9] Clump, M., Do psychology and biology majors differ in their study processes and learning styles? Retrieved on $22^{\text {nd }}$ May 2011 from http://eu-india.fh- joanneum.at/index.php?id=72 (2003).

[10] Wilson J., Lawson K., Novak S., Shah S., Salzman R., Pharmacy Students' Learning Styles Before and After a Problem-based Learning Experience retrieved on $3^{\text {rd }}$ July, 2010 from www.britannica.com/ (2006).

[11] Liu Y., A Comparative Study of Learning Styles between Online and Traditional Students.Journal of Educational Computing Research, retrieved on $3^{\text {rd } J u l y, ~} 2010$ from http://www.britannica.com/bps/additionalcontent/ (2007).

[12] Akkoyunlu, B., \& Soylu, M. Y., A Study of Student's Perceptions in a Blended Learning Environment Based on Different Learning Styles in Educational Technology \& Society, 11 (1), 183-193 (2008).

[13] Shannon S., Using Metacognitive strategies and Learning Styles to create self directed learners retrieved on $2^{\text {nd }}$ July, 2010 from http://www.auburn.edu/ witteje/ilsrj/Journal\%20Volumes/Fall\%202008\%20Volume\%201\%20PDFs/Metacognitive\%20Strategies $\% 20$ and\%20Learning\%20Styles.pdf (2008)

[14] Flavell, J., Metacognition and Cognitive Monitoring A New Area of Cognitive-Developmental Inquiry in American Psychological Association, Inc. Vol. 34, No. 10, 906-911(1979).

[15] Flavell, J. H., Miller, P. H., \& Miller, S. A. , Cognitive development Englewood Cliffs, NJ: Prentice-Hall(1993).

[16] Brown, A. L., Knowing When, Where and How to Remember: A Problem of Metacognition in Robert Glaser (Ed) Advances in Instructional Psychology. Hillsdale, N.J.: Eribaum (2002).

[17] Garland, E. L., The meaning of mindfulness: A second-order cybernetics of stress, metacognition, and coping. Complementary Health Practice Review, 12(1), 15-30 (2007).

[18] Thomas, D. C., Domain and development of cultural intelligence: The importance of mindfulness. Group \& Organization Management, 31(1), 78-99 (2006).

[19] Wells, A., Detached mindfulness In cognitive therapy: A metacognitive analysis and ten techniques. Journal of Rational-Emotive and Cognitive-Behavior Therapy, 23(4), 337-355(2005).

[20] Myers, Isabel Briggs; McCaulley Mary H.; Quenk, Naomi L.; Hammer, Allen L. (1998). MBTI Manual (A guide to the development and use of the Myers Briggs type indicator). Consulting Psychologists Press; 3rd ed edition. ISBN 0-89106-130-4 11. [21]The 16 MBTI $^{\circledR}$ Types Excerpted from Introduction to Type ${ }^{\circledR}$ by Isabel Briggs Myers published by CPP. Inc. Used with permission, retrieved from http://www.myersbriggs.org/my-mbti-personality-type/mbti-basics/the-16-mbti-types.asp

[22] Schraw, G. \& Dennison, R.S., Assessing metacognitive awareness. In Contemporary Educational Psychology, 19, 460-475(1994).

[23] Myers Briggs Type Indicator (MBTI) retrieved on 15/06/12 from http://web.cortland.edu/andersmd/learning/mbti.htm 